\title{
OS SABERES DAS PESCADORAS E PESCADORES ARTESANAIS: UM APRENDIZADO EMANCIPATÓRIO
}

\author{
THE KNOWLEDGE OF ARTISANAL FISHERMEN AND FISHERMEN: \\ AN EMANCIPATORY LEARNING
}

Indiamara Hummler Oda ${ }^{1}$

\begin{abstract}
Resumo
O presente artigo está alicerçado na trajetória de vida de pescadoras e pescadores artesanais, do litoral do Paraná, na comunidade pesqueira da cidade de Matinhos. Considerando a relevância dessa trajetória, o objetivo que se consolida por meio desses escritos, é de dar visibilidade à forma como essas práticas pesqueiras artesanais coexistem e resistem, respectivamente, com e aos obstáculos impositivos de uma economia capitalista, no universo de uma produção global. Emerge, no tocante ao referido, um desenvolvimento alternativo, em relação à subsistência da comunidade pesqueira, substanciada pela cultura de tradição caiçara. Seguindo os passos de uma metodologia etnográfica, em que consiste as narrativas que se configuram pelo observar das ações, pela disponibilidade de ouvir as representações, e assim vivenciando as experiências dos atores sujeitos desta pesquisa, foi possível, por intermédio desses instrumentais, o entendimento para a interpretação no contexto das análises do que aqui se propõe. É relevante a compreensão de que este trabalho, fruto de estudos de campo, foi conduzido em um processo de construção decolonial e, que por tal, aviva olhares reflexivos, sob diferentes ângulos à complexidade que se instaura na temática da pesca artesanal.
\end{abstract}

Palavras-chave: Cultura caiçara; Trajetórias; Coexistência; Alternativas de desenvolvimento.

\begin{abstract}
This article is based on the life trajectory of fishermen and artisanal fishermen, from the coast of Paraná, in the fishing community of the city of Matinhos. Considering the relevance of this trajectory, the objective that is consolidated through these writings is to give visibility to the way in which these artisanal fishing practices coexist and resist, respectively, with and against the imposing obstacles of a capitalist economy, in the universe of global production. An alternative development emerges, in relation to the subsistence of the fishing community, substantiated by the traditional caiçara culture. Following the steps of an ethnographic methodology, which consists of the narratives that are configured by observing the actions, by the availability to listen to the representations, and thus experiencing the experiences of the subject actors of this research, it was possible, through these instruments, the understanding for the interpretation in the context of the analysis of what is proposed here. It is important to understand that this work, the
\end{abstract}

\footnotetext{
* Artigo Original: Recebido em 30/09/2021 - Aprovado em 11/11/2021.

${ }^{1}$ Licenciada em Ciências Sociais, Especialista em Sociologia, Mestra em Ciências Ambientais, Doutoranda em Sociologia pela Universidade Federal do Paraná - UFPR, PR, Brasil.e-mail: indiaprof1963@gmail.com ORCID: https://orcid.org/0000-00022414-5031 (autor correspondente)
} 
result of field studies, was conducted in a process of decolonial construction and, as such, revives reflective views, from different angles to the complexity that is established in the theme of artisanal fishing.

Keywords: Caiçara culture; Trajectories; Coexistence; Development alternatives.

\section{Introdução}

É fato que a pesca artesanal, com os atores que a constituem, as pescadoras e os pescadores, está inserida em um universo de desenvolvimento econômico global. Entretanto, é fato também que o sentido da expressão estar inserida nesse universo não significa corresponder ao modelo tecnológico, industrial que a racionalidade capitalista impõe, distanciando e, ou anulando outras formas de subsistir. É no contexto desse discurso, que se estabelece a importância de trazer à tona as práticas das atividades pesqueiras artesanais, que embora coexistam com os modelos impostos pela racionalidade capitalista, entrelaçam a essa coexistência a resistência em manter viva a pesca de tradição.

Nesse sentido, afloram-se questionamentos aos valores, normas e regras de uma racionalidade capitalista, em que pese o condicionar dessas imposições a uma posição de inquestionáveis. Seguindo, assim, com o que se espera nesse trabalho, ou seja, visibilizar a partir das falas dos pescadores e das pescadoras aspectos relevantes em relação às atividades da pesca artesanal, diante dos quais estrutura-se um desenvolvimento alternativo. Avivar essa importância permite que esta discussão elucide outros caminhos enquanto meios de subsistência, que atravessam as fronteiras dos limites da racionalidade capitalista e desvinculam - se dos mesmos.

\section{As ameças da racioanlidade capitalista que se infiltram no universo da pesca artesanal}

Para entender de que forma essas ameaças se configuram nesse universo, parto de uma indagação: Quais são as qualificações que substanciam a expressão "ser um pescador e ser uma pescadora", no universo da pesca artesanal?

Visto que as falas dos sujeitos atores que integram esse trabalho direcionam e dão sentido a construção do mesmo, trago para o contexto da discussão, em um primeiro momento, as falas de um pescador e de uma pescadora, e no decorrer dos escritos, as falas de mais duas pescadoras. Identifico o pescador e as pescadoras por intermédio de números. Em relação à fala da pescadora 1 , que trabalha há 50 anos com a pesca artesanal:

Eu pertenço a colônia. É importante porque eu gosto e é preciso. Eu criei meus filhos, minhas neta, bisneta, aqui, tudo com a limpa de camarão. Eu pesquei com meu marido, eu saia com meu marido, e é muito bom. E tenho a carteira de pescadora e sou aposentada pela pesca e isso aqui para nós é um meio de vida, de sustento. Por mais que seja pouco, sempre se ganha 50 , $60,70,100$, então isso aqui é um meio de vida, se eu ficar sem isso aqui eu morro, pode me enterra. Eu sou mãe de pescador, mulher de pescadora, avó de pescadora e sou pescadora, com carteira de pescadora. Eu amo a minha profissão. Nois aqui, somos uma comunidade. Quem entende, dá valor. (Pescadora 1).

$\mathrm{Na}$ fala da pescadora 1, quando diz " Eu pertenço a colônia", a maneira como especifica o fazer parte como integrante da colônia, vem permeada por circusntanciais que reforçam o sentido desse pertencimento: “ sou mulher de pescador, mãe de pescador, avó de pescador...criei meus filhos, meus netos...se eu ficar sem isso aqui, eu morro"... Essa fala traz em si a complexidade na forma como atribui significados às suas representações enquanto pescadora que participa de forma ativa às atividades pesqueiras, estendendo a importância da pesca as suas gerações. Para referenciar a carteira de pescadora, expõe primeiro o que sente em relação à pesca, atribuindo esse sentimento a um meio de vida, a uma profissão que ama, mas esse amor é, e somente o é, valorizado no âmbito da comunidade. Dou continidade com a fala do pescador 2:

Divers@, Matinhos, v. 14, n. 2, p.126-134,jul./dez. 2021 
Eu entendo assim, deveria ter, no meu pensamento, a carteira de pescador para quem realmente pesca e deveria ter uma outra carteira, um outro tipo de coisa para as pessoas que não são direta, que são indiretamente pescador. A pessoa tinha que fazer uma carteira de descascadeira, de fileteira, ou de vendedor de peixe. Porque quem enfrenta o mar mesmo é totalmente diferente... Tem 250 pescadores diretos que pescam mesmo e no total quase 600 pescadores que dependem direto e indiretamente da pesca. Os indireto são os que limpam e vendem o que se pesca, que são os atravessadores. Mas todos dependem da pesca e todos têm carteira de pescador. Agora no cadastramento da tainha, eu faço uma documentação, uma licença, que eu sou pescador direto e negocio direto com as empresas. O IBAMA cuida muito dessas parte da tainha, controla muito. Daí eu tenho que ter a nota de produtor, que eu sou pescador direto e entrego para as empresa, para tirar as ova, essas coisa e tal... Chega o tempo da tainha, todo mundo vira pescador. É pedreiro, zelador, e o que acontece, o impacto vem em cima de nóis. Aquele peixe que o cara vai pescar ali, ao invés de pescar somente para ele, por encomenda, ele vai vender para o vizinho. Eles estão atrapalhando economicamente nóis também. Não tem vindo comprar peixe nosso aqui. Já estão espalhando pela cidade inteira, e nem pescador é. (Pescador 2). mesmo", pois segundo a sua concepção "é totalmente diferente"...

Mas, e as ameaças? Em que sentido estão inseridas nesse contexto? É em relação a respectiva carteira de pesca, então, referenciada no contexto do diálogo, que a ameaça se encontra, a saber: entre os pescadores e pescadoras artesanais, há aqueles e aquelas que nunca pescaram, mas fazem a carteira de pescador (a). Aqui surgem dois pontos a serem refletidos.

$\mathrm{O}$ primeiro volta-se ao pescador e à pescadora indiretos, que limpam e vendem o peixe. Embora não "enfrentem o mar", quando a pesca é suspensa por determinado período, quem possui a carteira de pescador e, ou pescadora, passa a ter direito ao seguro defeso, ou seja, a um subsídio do governo que garante um determinado salário no período de três meses em que a pesca não é permitida. Essa forma de obtenção de ganho, por intermédio do seguro defeso, quando atribuída àqueles, àquelas em que a carteira de pesca representa apenas uma forma de ganho, distancia-se muito dos valores que se apresentam na fala da pescadora 1 , também contidos na fala do pescador 2 quando referenciam as especificidades, já supracitadas, que identificam o que é ser um pescador(a).

O segundo ponto, que reflete a ameaça da racionalidade capitalista, está em: "Chega o tempo da tainha, todo mundo vira pescador. É pedreiro, zelador". A maneira como o economicamente é pensado por aqueles que Não São pescadores, mas "Viram" pescadores em determinada época, e somente nessa época, já direcionam o fato para um contexto onde pescar reveste-se como forma de lucrar, e o teor dessa constatação é muito diferente das representações que aparecem em "amo a profissão, somos uma comunidade, quem entende dá valor".
Em relação ao pescador 2 , já inicia a sua fala substanciada por contestações:"deveria ter, no meu pensamento, a carteira de pescador para quem realmente pesca". O seu posicionamento nos remete a questão das qualificações, ou seja, quem é merecedor de ser considerado pescador. Isso fica claro, quando na continuidade, esclarece o que pensa sobre a distribuição de funções em relação a quem é pescador direto e quem é indireto. Estende a esse esclarecimento a carteira de pesca que deveria ser atribuída a quem realmente "enfrenta o mar 


\section{Uma reflexão sobre atividades produtivas como experiências de construção alternativas ao desenvolvimento}

Estabelece-se, diante desses aspectos, situações conflituosas que surgem no contexto de coexistência entre as pescadoras e os pescadores de tradição e um mundo alicerçado pelo desenvolvimento global capitalista. Porém, há de se considerar como o ímpeto da resistência por manter as práticas de atividades pesqueiras aparece no contexto das falas. Refiro-me à forma como a pescadora e o pescador argumentam e defendem a produção da pesca artesanal, apontando meios de um desenvolvimento alternativo no contexto do desenvolvimento global capitalista.

$\mathrm{Na}$ busca de explicações que auxiliem a pensar sobre o exposto, em uma interação dialógica com as falas da pescadora e do pescador, atenho-me aos escritos de Dimas Floriani e Nicolas Floriani (2021, p. 37) que ao desenvolverem uma análise reflexiva sobre a produção de sujeitos plurais enquanto sujeitos de ação na relação sociedade/natureza, salientam sobre o mito do crescimento econômico, que é concebido dessa forma por manter acessa a ilusão de produzir bem-estar e felicidade a cada um e a todos os seres humanos. De forma reversa a essa ilusão do mito, segundo os autores, a exploração da natureza contínua e inapropriada, desencadeada por um modelo de desenvolvimento insustentável, tem como consequência uma crise civilizacional.

Partindo desses dados, os autores propõem um olhar reflexivo no tocante à ação desses sujeitos plurais voltadas às suas práticas das atividades produtivas como experiências de construção alternativas ao desenvolvimento. Essa constatação ganha consistência e faz sentido quando nos inclinamos a entender a existência e as experiências desses sujeitos ecológicos, no caso desse estudo, os sujeitos da pesca artesanal, vinculando-as as três dimensões apresentadas (FLORIANI; FLORIANI, 2021), a saber:

1) sua localização em espaços que designamos como "territórios da diferença" e que remetem a contextos de confronto com os demais atores sociais, principalmente aos hegemônicos (Estado, agentes econômicos de mercado, sistema das tecnociências, sistema cultural associado à racionalidade dos estilos de vida de consumo);
2) seus sistemas de práticas associados à gestão dos territórios, aos tipos de relação com a natureza e aos seus usos, com cuidados ecológicos de preservação e de reprodução das condições materiais de vida, de acordo com os princípios do socioambientalismo crítico;

3) suas experiências de vida e de associativismo voltadas a projetos de construção de autonomias socioambientais. (FLORIANI; FLORIANI, 2021, p. 40).

Essas dimensões, na prática, são substanciadas por encontros e desencontros, os quais por intermédio de conflitos políticos apresentam, de um lado, fatores externos hegemônicos, do modelo econômico, e, do outro lado, valores internos que buscam manter firme as suas identidades culturais. É possível perceber essa firmação ou reafirmação da identidade na fala do "pescador 2", pois quando reclama dos fatores externos ao contexto de suas tradições, anuncia a sua capacidade de politização enquanto sujeito integrante da comunidade pesqueira artesanal. Nesse sentido, aviva, por intermédio de seu posicionamento, a sua autonomia socioambiental.

Também com ênfase a pescadora 1 expõe, por meio da sua fala, o quão importante é fazer parte da comunidade da pesca artesanal, firmando, desse modo, a sua identidade enquanto pescadora atuante. No teor dessa questão, descortina -se o fato de que embora os pescadores e as pescadoras artesanais coexistam com o modelo de funcionamento hegemônico, as falas dos entrevistados aponta que este modelo não anula o modo de vida de tradições destes sujeitos. Dito de outra forma, a pesca artesanal foi, resiste e permanece, uma especificidade que integra a identidade cultural desses sujeitos de tradição.

O envolvimento dessa discussão remete-nos a significados relevantes presentes nas análises de Dimas Floriani e Nicolas Floriani (2021), ao refletirem sobre o processo de subjetivação voltada à produção e à reafirmação de identidades coletivas, nas palavras dos autores:

trata-se de um mecanismo que articula o individual com o coletivo, pois cada formação histórica produz modos diferentes de subjetivação que entram em relação, seja para estabelecer compromissos ou para 
opor-se às relações de poder e de saber existentes. O processo de subjetivação pode engendrar novos arranjos de reconhecimento e autoconhecimento dos sujeitos coletivos (ao redefinir identidades étnicas e culturais), de central importância para verificar como esse processo produz incidências sobre a organização sociopolítica das comunidades, pelo empoderamento dos atores subalternos e, neste caso, das populações tradicionais e indígenas em questão. (FLORIANI; FLORIANI, 2021, p. 51).

Há aqui uma interação entre os sistemas de práticas e uma consciência ética sobre a natureza, o saber cuidar e o bem viver. Nisso consiste, segundo as explicações dos autores (p.50), o vincular de questões que substanciam essa interação e que reflete-se na consciência ecológica, tais como: uma consciência cognitiva em torno das condições de produção, reprodução da vida e do ambiente socionatural (espaço, território, lugar), no qual os seres humanos desenvolvem suas atividades materiais e simbólicas; a existência de um mundo que se busca proteger, enquanto ser vivo, o que repercute na própria segurança atual e futura; o aspecto relacional ou à alteridade que se estende para além dos sujeitos singulares ou coletivos, ou seja, envolve um universo dimensional no que tange o pertencimento à natureza.

No patamar dessa discussão, recorro aos escritos de Diegues (1983) em relação aos pescadores artesanais caiçaras, que aclara aspectos dessa cultura de tradição. Segundo os escritos do autor, a pesca realizada nos moldes da categoria de pequena produção mercantil é dividida entre pescadoreslavradores, onde a produção se enquadra na noção de campesinato e pescadores artesanais, os quais se aproximam mais da corporação de ofício. Em meio às atividades da agricultura e ou da pesca artesanal, há de se considerar, através de um olhar diacrônico, que o sentido de território para a comunidade caiçara, vai além de um espaço demarcado. Diegues (1983) salienta que vivendo no interstício da Mata Atlântica e do mar, estuários, restingas e lagunas, reproduzindo seus modos de vida através de seus recursos naturais, os caiçaras constituíram- se em um território rico em diversidades biológica e cultural.
A forma como internalizam e exteriorizam esse modo de vida, é construída através dos saberes tradicionais no tocante aos seres do mar e da mata herdados, principalmente, de seus antepassados indígenas. Assumindo, desse modo, uma dimensão imensurável de pertencimento à natureza que transcende a noção de território enquanto meio físico explorado, é um lugar onde a interação das relações sociais com a natureza, dão um significado especial à existência. Mesmo considerando o fato de que o mito da economia tenha causado danos ao modo de existir dos caiçaras pescadores lavradores e, por tal, esse modo de existência já não se encontre em um estado "puro e límpido", os sujeitos - pescadores e pescadoras, buscam processos alternativos ao desenvolvimento enquanto comunidade pesqueira artesanal. Dessa forma, nos moldes da categoria de pequena produção mercantil, mantêm a autonomia socioambiental em coexistência com a racionalidade capitalista. Nisso consiste as argumentações de Dimas Floriani e Nicolas Floriani (2020):

Pensar em alternativas ao desenvolvimento, como sinônimo de busca por autonomia socioambiental, requer, portanto, não apenas conceber de outra forma mecanismos que permitam a uma organização social ser capaz de reproduzir-se materialmente, mas também de engendrar instituições em que a gestão, as normas, e os valores que regem as estratégias de sociabilidade se desloquem do atual sistema de racionalidade capitalista para outras racionalidades, com possibilidade de sobreporem-se ou então de coexistirem com a atualmente vigente. (FLORIANI; FLORIANI, 2020, p. 27).

Trazendo para o contexto dessa reflexão as análises de Stavenhagen (2018), sobre o etnodesenvolvimento enquanto uma dimensão ignorada no pensamento desenvolvimentista, o autor aponta que a abordagem do desenvolvimento alternativo procura usar e aproveitar as tradições culturais existentes e, nesse sentido, não as rejeita a priori como obstáculos ao desenvolvimento. Esta abordagem nova e alternativa é substanciada pela pretensão de ser mais participante do que tecnocrática. É uma alternativa voltada para e 
pelo seu povo, sejam eles camponeses ou operários, aldeões ou favelados, enquanto participantes em todos os níveis de desenvolvimento. Considero pertinente atribuir a esse cenário, os pescadores e as pescadoras artesanais, visto que as suas práticas pesqueiras se constituem nesse contexto de desenvolvimento alternativo. Seguindo com o pensamento do autor, este salienta que esta alternativa de desenvolvimento se desloca dos escritórios dos burocratas para o seu verdadeiro lugar, ou seja, as bases. De acordo com suas palavras:

\begin{abstract}
Além disso a abordagem do desenvolvimento alternativo estaria baseada, sempre que possível, no uso dos recursos locais quer sejam naturais, técnicos ou humanos; ou seja, ela se orienta para a auto-sustentação, nos níveis local, nacional e regional. A auto-sustentação não significa autarquia, a qual não é sequer possível ou desejável, no mundo interdependente de nossos dias; ela significa, no entanto, que o Terceiro Mundo deve contar, basicamente, com suas próprias forças e recursos, mais do que esperar soluções para seus problemas a partir do mundo industrializado. (STAVENHAGEN, 2018, p. 19).
\end{abstract}

Stavenhagen (2018), traz uma abordagem relevante em relação ao fato da teoria do desenvolvimento ir além do fracasso de importar uma economia industrializada, tal qual foi formulada nos países desenvolvidos, para os países de Terceiro Mundo. Acrescenta, a esse fracasso, a questão de ter sido ignorado a existência de economias que se distanciam dos parâmetros estabelecidos pelo desenvolvimento industrial. $\mathrm{O}$ autor faz referência, nessa abordagem, a economia camponesa e retrata como essa economia foi desprezada, pelo fato de ser desinteressante e, diante do exposto, marginalizada frente as exigências econômicas de um setor moderno.

Há, porém, nessas análises de Stavenhagen (2018), o interesse em emergir desse contexto, olhares para outras alternativas de desenvolvimento como já supracitado. Aviva, com esse propósito, o fato de que as crises de alimento da década de 70 conduziram a uma redescoberta do campesinato. O que nos traz analiticamente, são informações que apontam as consequências das organizações internacionais do desenvolvimento industrial do sistema moderno, as quais tiveram custos elevadíssimos e sem êxito. Esses fatos repercutiram no crescente aumento da pobreza rural, principalmente nos países de Terceiro Mundo. Foi nesse cenário que olhares se debruçaram para o campesinato, e, assim, foi redescoberto como uma solução.

Os apontamentos de Stavenhagen (2018), despertam o fato de que mesmo envolta por condições desfavoráveis, dentre as quais a impotência de uma economia industrializada frente a planejamentos sobre a natureza da economia da cultura e da sociedade camponesa, a economia camponesa não desapareceu, mas de forma resistente, se dispõe a uma longa sobrevivência. No complemento dessa discussão, Stavenhagen discorre sobre a economia doméstica como um fator crucial no contexto dessa dinâmica, ressaltando aspectos voltados que refletem a função social e cultural bem como determinam os padrões de consumo a reprodução da força de trabalho. A saber: a criação dos filhos, a educação, a segurança, entre outros. Vinculado e interagindo com esses aspectos, o autor argumenta sobre o reconhecimento e a reavaliação do papel das mulheres enquanto sujeitos integrantes desse cenário social e econômico. Segundo Stavenhagen (2018):

A descoberta da unidade doméstica como uma parte importante da economia está ligada à reavaliação do papel das mulheres na dinâmica social e econômica e isto, por sua vez, decorre, diretamente, das reivindicações ideológicas e políticas dos movimentos feministas nos últimos anos. Uma ciência social machista era incapaz de perceber a significância da economia doméstica, contaminando, assim, as teorias sobre o desenvolvimento. (STAVENHAGEN, 2018, p. 23).

$4 \mathrm{Um}$ pouco mais sobre a participação da mulher pescadora no contexto da produção: Uma realidade realizável

Divers@, Matinhos, v. 14, n. 2, p. 126-134,jul./dez. 2021 
Considerando a dimensão da relevância em relação às unidades domésticas e a reavaliação da mulher no que tange a função social e cultural no cenário da economia, estendo esse contexto à participação das mulheres pescadoras, enquanto integrantes ativas, no universo de uma economia alternativa, doméstica, em que se constitui a pesca artesanal caiçara. Reporto-me, para substanciar esse objetivo, a fala da pescadora 1:

O caiçara para mim é a pessoa que nasceu aqui e que toda vida dependeu da pesca. Eu vim para cá, em 1970. Mas eu me considero um caiçara. Eu gosto do meu peixe. Criei meus filhos com o pirão de água, tão aí, e nunca morreram. Naquele tempo não tinha cesta, nem bolsa família, nem nada. Era o pirão de água. Nóis coava a farinha e fazia o pirãozinho assim. Uma coisa que eu acho muito falta, quando nóis tinha matéria aqui, é os cursos que tinha aqui. Nóis tinha vários curso aqui. Eu tenho um monte de diploma dos curso que eu fiz. Agora, aqui, tem poquinha mulher, mas tem dias que tem bastante. Elas tão aqui ganhando o dinheirinho delas, mas elas podiam fazer outra coisa, outra atividade, sobre a pesca, da pesca. Mas não tem, é só limpar o camarão. Eu sei fazer flor, pão, doce, tudo que aprendi aqui. Eu fazia sabão. Eu sei faze muita coisa, que dava um dinheirinho, mas elas não sabe. Eu só não sei faze é remenda rede, mas o resto. (Pescadora 1).

$\mathrm{O}$ que a fala enaltece? $\mathrm{O}$ " nascer" caiçara e ser pescador; o não nascer caiçara, mas pertencer a esse universo; o pirão e o peixe enquanto sustento caiçara; outras atividades como fazer pão, flor, sabão, que embora sejam outras, fazem parte "da pesca e sobre a pesca". Esses referenciais trazem consigo, uma bagagem social, cultural que alicerça a economia doméstica com a participação da mulher pescadora, no tocante à produção, ao consumo e à reprodução da força de trabalho.

A entrega da pescadora ao universo caiçara, permite-nos enxergar o que há pouco foi exposto. Ou seja, que a pesca artesanal enquanto uma alternativa de desenvolvimento no contexto da economia, não desapareceu, mas de forma resistente, se dispõe a uma longa sobrevivência. Dito de outra maneira, pensar essa resistência como princípio efetivo de combates e movimentos que confrontam a dinâmica do capital e conduzem a formas originais de ação e discurso.

Essa ação e discurso podem ser compreendidos como uma emergência estratégica do comum. Busco essa compreensão da emergência estratégica do comum, nas reflexões de Dardot e Laval (2017), que apontam a necessidade de produzir visões novas sobre o além do capitalismo, pensar as condições e as formas possíveis do agir comum, esclarecer os princípios que podem orientar as lutas, unir as práticas dispersas à forma que uma nova instituição geral das sociedades poderia assumir.

De acordo com Dardot e Laval (2017, p.19), o comum se tornou a designação de um regime de práticas, lutas, instituições e pesquisas que abrem as portas para um futuro não capitalista. Detenho-me, aqui, a interagir o entendimento do "comum" com as práticas e lutas dos pescadores e pescadoras artesanais frente às imposições da economia capitalista, substanciada por uma racionalidade neoliberal, àqueles que são por esta marginalizados. Nisso consiste o fato de que os pescadores e pescadoras, enquanto integrantes de uma comunidade pesqueira caiçara, encontram-se e, ou, são "percebidos" pelos "olhos" da racionalidade capitalista, como excluídos, visto que não compartilham, ou não se enquadram nos valores estabelecidos por essa racionalidade. Considerando esse fato, e prosseguindo com o pensamento de Dardot e Laval (2017, p. 26), o agir comum atenta para que sujeitos se engajem juntos numa mesma tarefa e, agindo desse modo, produzam normas jurídicas e morais que regulem sua ação.

Dessa forma, a obrigação que se instaura no princípio político do comum está centrada entre os que participam de uma mesma atividade ou de uma mesma tarefa, excluindo a possibilidade de a obrigação se fundamentar num pertencimento que seria independente da atividade. Nas palavras dos autores:

O comum não é um bem, e o plural nada muda nesse aspecto, porque ele não é um objeto ao qual deva tender a vontade, seja para possuí-lo, seja para constituí-lo. O comum é o princípio político a partir do qual devemos 
construir comuns e ao qual devemos nos reportar para preservá-los, ampliálos e lhes dar vida. (DARDOT; LAVAL, 2017, p. 53).

O significado que une os termos e os coloca em movimento é a ação conscientizadora de cada sujeito que faz parte dessa engrenagem política, possibilitando o preservar, o ampliar e o dar vida ao comum e, por conseguinte, construir comuns. Partindo desses princípios, trago as falas das pescadoras 3 e 4 :

Meu pai já era pescador. Tenho sessenta anos, e vendia camarão para o meu pai desde os dez anos. Ele trazia do mar e não tinha esse mercado tempo não tinha o mercado, era na beira da praia, a gente vendia camarão lá. Naquele tempo pegava camarão com espinhel, não tinha rede. Eu ajudava ele, vendia, limpava camarão, limpava peixe, mas meu forte mesmo é limpar camarão, peixe eu quase não limpo. Esse dinheirinho aqui, dá prá gente fazer muita coisa. Eu me considero uma pescadora, ser pescadora é tudo, é uma profissão muito boa. (Pescadora 3).

Eu sou nascida aqui, eu sou caiçara mesmo. Eu cresci na pesca, e já trabalhei em tudo quanto é coisa. Trabalhei com o caminhão do misturado, trabalhei na rua. Eu cresci na pesca. O meu vô era pescador. Aqui é tudo em família. O meu tio é marido de uma mulher que trabalha aqui, e pescador também. É tudo em família. A pesca é o nosso trabalho, o nosso ganha pão. É aqui que tiro o alimento das criança. Eu gosto muito do que eu faço. Eu tenho onze filhos, agora treze, porque eu tenho dois neto que eu crio. Eu consegui criar os meus filhos, graças à Deus, com o camarão. (Pescadora 4).
As falas apontam o comum avivando uma responsabilidade e reciprocidade que alimentam o princípio político de estarem engajadas em uma mesma atividade, ou seja, a pesca nas suas mais diferentes, porém, integradas funções. Reiterando o posicionamento dos autores em que o comum deve ser compreendido como uma co-atividade, é esta co-atividade que fortalece, preserva, e dá vida a pesca artesanal. Assim, a prática do comum enquanto uma realidade no cotidiano tanto das mulheres quanto dos homens pescadores artesanais, possibilita a concretude de um universo que distancia esses sujeitos da pesca da condição de mero capital humano. Complemento o contextualizado, com a citação dos autores, (DARDOT; LAVAL, 2017):

O comum não é nem um princípio moral abstrato, nem um tipo de homem. Os homens que agem para construir o comum não se deixam enquadrar previamente num tipo psicológico identificável, nem numa categoria social de contornos definidos: eles são o que suas práticas fazem deles. (DARDOT; LAVAL, 2017, p. 53).

Seguindo essa linha de pensamento, reitero o dito com as abordagens de Santos (2003) que possibilitam um enfrentamento à universalização do paradigma ocidental, em sua proposta voltada à hermenêutica da suspensão, ou seja: uma ruptura com a ruptura epistemológica ocidental moderna - que se assume como única e universal; uma outra percepção em relação ao senso comum - que deve ser distanciada da negatividade que lhe foi cravada; o repensar valores, o reconstruir conhecimento, o ressignificar relações - em um cenário que se estende às esferas da cultura; da ciência; dos saberes dos povos tradicionais.

\section{Finalizando com um olhar Decolonial}

Termino os escritos com a mesma ênfase a que me dispus em relação à visibilizar a pesca artesanal, no tocante à prática dessas atividades como um forma de desenvolvimento alternativa frente às imposições de uma produção global capitalista. Um resgate ao respeito no que tange a forma de perceber e interpretar o outro, combatendo, nesse sentido, as diversas opressões. Dito de outra maneira: a 
superação aos paradigmas vigentes, trazendo à tona o paradigma emancipatório.

\section{Referências}

DARDOT, Pierre; LAVAL, Christian. Comum: Ensaios sobre a revolução no século XXI. Boitempo: São Paulo; p. 2-60, 2017.

DIEGUES, Antonio C. S. Pescadores, camponeses e trabalhadores do mar, São Paulo, Ática.1983

FLORIANI, Dimas e FLORIANI, Nicolas, Ecologia das práticas e dos saberes para o desenvolvimento local: territórios de autonomia socioambiental em algumas comunidades tradicionais do centro-sul do Estado do Paraná. Revista Latinoamericana Polis $n^{\circ}$ 56, p.24-39, 2020.

FLORIANI, D.; FLORIANI, N. Produção e constituição de sujeitos ecológicos plurais: experiências com algumas populações rurais tradicionais e indicadores de avaliação de autonomia socioambiental. In: FOLMANN, J. I. (Org.) Ecologia Integral: abordagens (im)pertinentes. Novo Hamburgo: Casa Leiria, 2021. v. 3, p.37-60.

SANTOS, B. S. Ciência e senso comum. In: SANTOS, B. S. Introdução a uma ciência pósmoderna. São Paulo: Graal, 2003.

STAVENHAGEN, R. Etnodesenvolvimento: Uma dimensão Ignorada no Pensamento Desenvolvimentista. Anuário Antropológico, v. 9, n. 1, p. 11-44, 2018. 